\title{
Carbon Dioxide Adsorption on Grafted Nanofibrous Adsorbents Functionalized Using Different Amines
}

\section{OPEN ACCESS}

Edited by:

Youngjune Jason Park, Gwangju Institute of Science and

Technology, South Korea

Reviewed by:

Eduardo René Perez Gonzalez, São Paulo State University, Brazil

Selmiye Alkan Gürsel,

Sabanci University, Turkey

Dong-Yeun Koh,

Georgia Institute of Technology,

United States

*Correspondence:

Anongnat Somwangthanaroj

anongnat.s@chula.ac.th

Soorathep Kheawhom

soorathep.k@chula.ac.th

Specialty section:

This article was submitted to

Carbon Capture, Storage, and

Utilization,

a section of the journal

Frontiers in Energy Research

Received: 15 August 2019 Accepted: 28 November 2019 Published: 10 December 2019

Citation:

Abbasi A, Nasef MM, Babadi FE, Faridi-Majidi R, Takeshi M, Abouzari-Lotf E, Choong T,

Somwangthanaroj $A$ and Kheawhom S (2019) Carbon Dioxide Adsorption on Grafted Nanofibrous Adsorbents Functionalized Using Different Amines.

Front. Energy Res. 7:145 doi: 10.3389/fenrg.2019.00145

\begin{abstract}
Ali Abbasi ${ }^{1,2}$, Mohamed Mahmoud Nasef ${ }^{3}$, Farahnaz Eghbali Babadi ${ }^{1}$, Reza Faridi-Majidi ${ }^{4}$ Matsuura Takeshi ${ }^{5}$, Ebrahim Abouzari-Lotf ${ }^{6,7}$, Thomas Choong ${ }^{8}$, Anongnat Somwangthanaroj ${ }^{1 *}$ and Soorathep Kheawhom ${ }^{1,2 *}$

${ }^{1}$ Department of Chemical Engineering, Faculty of Engineering, Chulalongkorn University, Bangkok, Thailand, ${ }^{2}$ Research Unit of Advanced Materials for Energy Storage, Chulalongkorn University, Bangkok, Thailand, ${ }^{3}$ Chemical Engineering Department, Universiti Teknologi PETRONAS, Seri Iskandar, Malaysia, ${ }^{4}$ Department of Medical Nanotechnology, School of Advanced Technologies in Medicine, Tehran University of Medical Sciences, Tehran, Iran, ${ }^{5}$ Department of Chemical \& Biological Engineering, University of Ottawa, Ottawa, ON, Canada, ${ }^{6} \mathrm{Helmholtz}$ Institute UIm (HIU) Electrochemical Energy Storage, UIm, Germany, ${ }^{7}$ Advanced Materials Research Group, Center of Hydrogen Energy, Institute of Future Energy, Universiti Teknologi Malaysia, Kuala Lumpur, Malaysia, ${ }^{8}$ Department of Chemical and Environmental Engineering, Universiti Putra Malaysia, Selangor, Malaysia
\end{abstract}

Of late, the demand for new $\mathrm{CO}_{2}$ adsorbents with high adsorption capacity and stability is growing very fast. Nanofibrous adsorbents are potential materials for such application with most attempts made on carbon nanofibers. In this study, a series of electrospun nanofibrous adsorbents containing amines were prepared using a 3-stage promising approach and tested comparatively for $\mathrm{CO}_{2}$ capture. The preparation of adsorbents involved electrospinning of syndiotactic polypropylene (s-PP) solution, radiation-induced grafting (RIG) of glycidyl methacrylate (GMA) onto electrospun nanofibers, and functionalization of poly-GMA grafted S-PP nanofibrous mats with different amines, including ethanolamine (EA) diethylamine (DEA) and triethylamine (TEA). The effect of different amination parameters: namely, amine concentration, reaction time, temperature, and degree of grafting (DG) on the degree of amination (DA), was evaluated. The nanofibrous mats containing amine were tested for $\mathrm{CO}_{2}$ adsorption in a fixed bed column operated under various parameters such as amine density, amine type, initial $\mathrm{CO}_{2}$ concentration and temperature. The adsorbents recorded $\mathrm{CO}_{2}$ adsorption capacities of 2.87, 2.06, and $0.94 \mathrm{mmol} / \mathrm{g}$ for EA-, DEA- and TEA-containing adsorbents, respectively, at $30^{\circ} \mathrm{C}$ using initial $\mathrm{CO}_{2}$ concentration of $15 \%$. This was coupled with the same order of high amine efficiency of 75,57 , and $31 \%$. Results demonstrated that the nanofibrous adsorbent containing amine had strong potential for $\mathrm{CO}_{2}$ capture application.

Keywords: radiation-induced grafting, electrospun nanofibers, $\mathrm{CO}_{2}$ adsorption, poly(glycidyl methacrylate), ethanolamine, diethylamine, triethylamine 


\section{INTRODUCTION}

Nowadays, fossil fuels are the primary source for coping with high energy demand around the world. Consequently, this has led to a large amount of carbon dioxide $\left(\mathrm{CO}_{2}\right)$ being released into the atmosphere. Over the past 50 years, the amount of $\mathrm{CO}_{2}$ has risen from $310 \mathrm{ppm}$ to more than $390 \mathrm{ppm}$ bringing about air pollution and global warming (Wahiduzzaman et al., 2015). Although there are several techniques commercially available for mitigating $\mathrm{CO}_{2}$ released into the atmosphere, there is still a high demand for highly efficient and low-cost adsorbents for capturing $\mathrm{CO}_{2}$ from various systems, including flue gas.

The most commonly used technique for $\mathrm{CO}_{2}$ capture is liquid amine absorption, also known as amine scrubbing. However, this technique has some limitations, including high energy demand, amine decomposition during regeneration and equipment corrosion (Xiao et al., 2016). Alternatively, adsorption over solid substrates has attracted greater attention (Hosseini et al., 2015; Heo et al., 2019). Of the various adsorbent development approaches, introducing amine functional groups into porous substrates is an effective strategy for the development of highly selective solid $\mathrm{CO}_{2}$ adsorbents with high adsorption capacity. Even though solid-amine based adsorbents also suffer from high energy demand during the regeneration process (Hicks et al., 2008), using a non-aqueous process for the adsorption and desorption is one of their advantages over liquid amine absorption.

Porous substrates of polymeric microfibers offer several advantages over other materials. This is due to its excellent flexibility, easy regeneration, humidity-aided adsorption, lowpressure loss, and suitability for low-temperature applications (Zhuang et al., 2013). Nevertheless, these adsorbents suffer from low adsorption capacity owing to the lack of high access to amine functional groups. One possible approach to improve work capacity and efficiency of microfibrous adsorbents is to increase the surface area of the fibers by moving from micro- to nano-scaled substrates such as carbon and polymer nanofibers.

Nanofibers are one-dimensional structures with threedimensional (3D) morphology offering several advantages: namely, porous interconnected architecture, high surface area, and the ability to control their functionality and morphology. Since adsorption happens on the surface of materials, increasing the surface to volume ratio results in better access to carbon dioxide molecules to amine functional groups, leading to higher adsorption efficiency. Moreover, the porous interconnected structure of the nanofibrous mats could potentially decrease the pressure drop during the adsorption, leading to lower energy requirements for the process. Furthermore, for nanoscale fibers, there is another factor affecting adsorption efficiency and pressure drop called slip flow. The ratio of gas mean free path to the fiber radius is called Knudsen number. When Knudsen number becomes non-negligible, the continuous flow theory, which does not reckon the molecular nature of air, begins to fail. In this case, the speed of air molecules at the surface of fibers is not zero, and slip flow prevails. As a result, the drag force on the fiber surface and, therefore, pressure drop decreases (Graham et al., 2002).
Different techniques have been used to produce nanofibers, such as phase separation (Van De Witte et al., 1996) and template synthesis (Chakarvarti and Vetter, 1998). Electrospinning is the most versatile and commonly nanofibers producing method (Abbasi et al., 2014). Due to their unique properties, nanofibers have become favorable alternative substrates for $\mathrm{CO}_{2}$ adsorbents development.

In many studies, electrospun carbon nanofibers were tested as $\mathrm{CO}_{2}$ adsorbent (Hong et al., 2014; Iqbal et al., 2017; Kim et al., 2017). On the other hand, polymeric nanofibers were subjected to a limited number of investigations for such application. As a promising material for adsorption applications, nanofibers are usually modified using different methods to introduce the requisite functionality and properties. Dip-coating, interfacial polymerization and radiation-induced grafting (RIG) are standard techniques used in this regard. Interestingly, RIG is very promising because of its ability to permanently modify chemical and physical characteristics of various forms of polymeric substrates (films, particles, or fibers) without having a significant impact on their inherent properties (Abbasi et al., 2018).

It is worth noting that electrospun nanofibers of polyacrylonitrile (PAN) were used as a substrate for hosting $\mathrm{Cu}-$ based metal-organic frameworks (MOFs). Such MOFs, which are known for their high surface area, high adsorption, and storage capacity for $\mathrm{CO}_{2}$ gas, boosted adsorbent performance. In another study, polyamide-6/amine-functionalized CNT composite nanofibers were impregnated with polyethyleneimine (PEI) to enhance $\mathrm{CO}_{2}$ adsorption capacity and selectivity. As a result, maximum adsorption capacity of $1.16 \mathrm{mmol}$ $\mathrm{CO}_{2} / \mathrm{g}$-adsorbent was achieved, which is comparable with other polymer-based $\mathrm{CO}_{2}$ adsorbents (Zainab et al., 2017). PAN nanofibers were also functionalized with different amines and tested for efficient transport of humid $\mathrm{CO}_{2}$. Thus, $\mathrm{CO}_{2}$ capture capacity of the amine-containing PAN nanofibers increased due to the change in the chemical and morphological structure of the fibers (Olivieri et al., 2018).

In a previous study, a combination of electrospinning of syndiotactic polypropylene (s-PP) followed by RIG by glycidyl methacrylate (GMA) and chemical modification using ethanolamine (EA) was used to develop a new $\mathrm{CO}_{2}$ adsorbent. The adsorbent showed an impressive $\mathrm{CO}_{2}$ capture performance (Abbasi et al., 2019). However, the presence of poly-GMA in the grafted nanofibers with its epoxy group, which allows the introduction of different amine groups that may have a substantial impact on the performance of the adsorbent, has not been explored so far. The objective of this study is therefore to comparatively investigate the effect of functionalization of poly-GMA grafted s-PP nanofibrous sheets using different amines including ethanolamine (EA), diethylamine (DEA) and triethylamine (TEA) on $\mathrm{CO}_{2}$ adsorption capacity under different fixed-bed column parameters. The study also involves a thorough investigation of the effects of amination parameters such as amine concentration, reaction time, temperature, and degree of grafting (DG) on the degree of amination (DA).

Combining electrospinning with RIG provides a versatile approach for synthesizing a new group of materials with several 
benefits. High surface area, the capability to introduce various functional groups, controlling the porosity of the material, and adjusting the density of introduced functional groups are some of the advantages offered by this approach. It leads to the synthesis of various materials with diverse applications such as ion exchange membranes (Abouzari-Lotf et al., 2017). For $\mathrm{CO}_{2}$ adsorption, it could be translated to the ability to tune the material to be suitable for various flow rates, different $\mathrm{CO}_{2}$ concentrations in the feed, presence of various impurities, and different temperatures. The adsorbed $\mathrm{CO}_{2}$ could be used in various applications, such as replacing hazardous starting materials for the synthesis of chemicals, e.g., replacing isocyanates and phosgene in the synthesis of carbamate-type fungicides (Aresta and Quaranta, 1997). It is worth noting that this is a fundamental study, and more investigation is required on scale-up capability, cost analysis, and deep engineering before the technique could be adopted for industrial application.

\section{MATERIALS AND METHODS}

\section{Materials}

EA (purity $\geq 99 \%$ ), DEA (purity $\geq 99.5 \%$ ), TEA (purity $\geq$ 99\%), decahydronaphthalene (decalin) (reagent grade, 98\%), dimethylformamide (DMF, $\geq 99.8 \%$ ), GMA (purity $\geq 99 \%$ ), s-PP $(\mathrm{Mw}=174,000 ; \mathrm{Mn}=75,000)$ and tetrahydrofuran (THF) (anhydrous, $\geq 99.9 \%$ ) were supplied by Sigma-Aldrich, Singapore. Acetone (Analytical grade, Fischer Scientific, USA) and methanol (Merck Millipore, USA) were used, as received, without any further purification. $\mathrm{CO}_{2}$ and nitrogen $\left(\mathrm{N}_{2}\right)$ gas ( $>99.98 \%$ purity) were supplied by Linde AG, Malaysia. Deionized (DI) water was used for washing and preparation of solutions.

\section{Preparation of Adsorbents \\ Electrospinning of s-PP Nanofibers}

$\mathrm{s}$-PP nanofibers with a specific surface area of more than $2.0 \mathrm{~m}^{2} / \mathrm{g}$ were electrospun via $7.5 \mathrm{wt} / \mathrm{v} \%$ solution of polymer in a solvent containing a mixture of decalin, acetone and DMF with a weight ratio of 80:10:10 under optimum conditions, as reported in a previous communication (Abbasi et al., 2018, 2019). The obtained nanofibers were dried at $60^{\circ} \mathrm{C}$ for $24 \mathrm{~h}$ to remove the residual solvents.

\section{Grafting of GMA Onto s-PP Nanofibers}

GMA was grafted onto s-PP nanofibers using a pre-irradiation technique. Thus, some nanofibrous sheets $(4 \times 4) \mathrm{cm}$ were placed in vacuum-sealed polyethylene bags and irradiated on dry ice using a universal electron beam accelerator (NHV-Nissin High Voltage, EPS3000, Cockroft Walton type, Japan) with an acceleration voltage of $1 \mathrm{MeV}$ and a beam current of $10 \mathrm{~mA}$ to a total dose in the range of 40-200 kGy. The irradiated samples were kept inside a low-temperature freezer at $-40^{\circ} \mathrm{C}$ and used for grafting reactions within 3 days. The degree of grafting (DG) representing the amount of poly(GMA) grafted in s-PP substrates was varied by changing the grafting parameters such as monomer concentration, temperature, and time. Details of the effect of grafting parameters on DG have been reported elsewhere (Abbasi et al., 2018).

\section{Amination of Poly(GMA)-Grafted Nanofibers}

Three amination agents, including EA (primary amine), DEA (secondary amine) and TEA (tertiary amine) were used to functionalize the poly(GMA) grafted s-PP nanofibrous samples using 3 different reactions. The amination reaction proceeded by the opening of the epoxy rings as presented in the grafted poly(GMA) side chains. The reaction was carried out by immersing a sample of poly(GMA) grafted s-PP nanofibrous sheets of known weight in a solution of amination agent diluted in water to concentrations in the range of $20-100 \%(\mathrm{v} / \mathrm{v})$ for EA and DEA and a volume ratio of 50:50 (v/v) for TEA. The solution was stirred at temperatures in the range of $25-70^{\circ} \mathrm{C}$ under reflux condition for the amination using EA and DEA. It was noted that performing the amination reaction using TEA at higher temperatures made the samples very brittle and very difficult to handle in adsorption experiments. So, the reaction was carried out at $30^{\circ} \mathrm{C}$ within a longer time in order that the reaction be fully completed. The reaction continued until the degree of amination (DA) reached a plateau. Then, the samples were extracted, rinsed with DI water several times to remove all un-reacted amines and dried at $60^{\circ} \mathrm{C}$ in a vacuum oven for $12 \mathrm{~h}$. Finally, the samples were weighed. DA was calculated according to Equation (1) (Choi et al., 1999):

$$
\mathrm{DA}=\frac{\left(\frac{W_{a}-W_{g}}{M_{w a}}\right)}{\left(\frac{W_{g}-W_{0}}{142.15}\right)} \times 100
$$

where $W_{0}, W_{g}$, and $W_{a}$ are the weights of the samples before grafting, after grafting and after amination, respectively. $M_{w a}$ is the molecular weight of the amination agent, and the molecular weight of GMA is 142.15 . Furthermore, amine density is defined as the moles of the amine functional groups per gram of the adsorbent and is determined as in Equation (2):

$$
\text { Amine density }(\mathrm{mmol} / \mathrm{g})=\frac{\left(\frac{W_{a}-W_{g}}{W_{a}}\right)}{\left(M_{w a}\right)} \times 1000
$$

\section{$\mathrm{CO}_{2}$ Adsorption Tests}

A fixed bed adsorption column fabricated by Solutions Sdn Bhd, Malaysia, was used to test the $\mathrm{CO}_{2}$ adsorption capacity of the prepared samples under dynamic condition. A stainless-steel column with a height of $330 \mathrm{~mm}$ and an internal diameter of $250 \mathrm{~mm}$ was equipped with a porous plate located at a height of $30 \mathrm{~mm}$, as a sample holder. Temperature control was carried out using a heating element coiled around the column and two K-type thermocouples, with an accuracy of $\pm 1.5^{\circ} \mathrm{C}$ located at a height of 75 and $280 \mathrm{~mm}$ from the column base.

A gas mixture of $\mathrm{CO}_{2} / \mathrm{N}_{2}$ with a total flow rate of $50 \mathrm{ml} / \mathrm{min}$ with different $\mathrm{CO}_{2}$ concentrations was used for adsorption experiments at atmospheric pressure. The flow of $\mathrm{CO}_{2}$ and $\mathrm{N}_{2}$ gasses was accurately controlled by two mass flow controllers 
(GFC series, Dwyer Instruments, USA) in the range of 1-50 and $1-100 \mathrm{ml} / \mathrm{min}$, respectively. An online $\mathrm{CO}_{2}$ analyzer (GfG Gesellschaft für Gerätebau IR 24) with a maximum detection limit of $50 \mathrm{vol} \%$ was used to monitor $\mathrm{CO}_{2}$ concentration before and after adsorption. Nitrogen gas was humidified via a water bubbler at $60^{\circ} \mathrm{C}$ and then mixed with $\mathrm{CO}_{2}$. The relative humidity of the gas stream was about $80 \%$ as determined by FisherScientific lab hygrometer.

The calculation of the dynamic adsorption capacity $(q)$ of the samples was carried out as in Equation (3) (Serna-Guerrero and Sayari, 2010):

$$
q=\frac{F \times C_{0} \times t_{q}}{W}
$$

where $F$ is total flow rate $(\mathrm{mmol} / \mathrm{s}), C_{0}$ is the initial concentration of $\mathrm{CO}_{2}, W$ is the weight of the adsorbent $(\mathrm{g})$, and $t_{q}$ is the stoichiometric time (s), calculated using the breakthrough curve according to Equation (4) (Serna-Guerrero and Sayari, 2010).

$$
t_{q}=\int_{0}^{\infty}\left(1-\frac{C}{C_{0}}\right) d t
$$

where $C$ and $C_{0}$ are $\mathrm{CO}_{2}$ concentrations at the inlet and the outlet gas streams, respectively.

The ratio of the moles of $\mathrm{CO}_{2}$ adsorbed on the material to the moles of nitrogen available on the sample is defined as amine efficiency. Amine type and presence or absence of water molecules determine the maximum amine efficiency of an adsorbent. Maximum amine efficiency of all types of amines (primary, secondary, and tertiary) in humid conditions used in these experiments is 1 . Amine efficiency was calculated according to Equation (5):

$$
\text { Amine efficiency }(\%)=\frac{q}{\text { amine density }} \times 100
$$

where amine density is the moles of the amine functional groups per gram of the adsorbent and $q$ is the adsorption capacity.

Furthermore, the influence of initial $\mathrm{CO}_{2}$ concentration, temperature and degree of grafting/amination on the adsorption capacity of the samples was investigated. Initial $\mathrm{CO}_{2}$ concentration, temperature and DG were changed in the range of $5-15 \%, 30-50^{\circ} \mathrm{C}$, and $150-400 \%$, respectively.

\section{Characterization of Adsorbents}

A scanning electron microscope (SEM, Hitachi S3400N, Japan) with an acceleration voltage of $10 \mathrm{kV}$ and a magnification of $1000-5000 \mathrm{x}$ was used to study the morphology of the samples after being coated with gold. To estimate the average fiber diameter of nanofibers, the diameters of 30 random fibers of each sample were measured and used. The changes in the chemical composition of the samples were investigated using a Nexus 670 Thermo Nicolet FTIR in the frequency range of 4,000-400 $\mathrm{cm}^{-1}$ with a resolution of $4 \mathrm{~cm}^{-1}$ and five-time scans.

The thermal properties such as melting temperature of the samples were investigated using a differential scanning calorimetry (DSC: Q200 TA Instrument, USA) under nitrogen

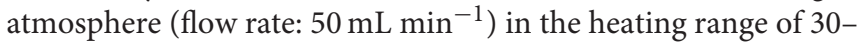
$300^{\circ} \mathrm{C}$ at a heating rate of $10^{\circ} \mathrm{C} \mathrm{min}^{-1}$. The thermal stability of the samples was monitored by thermogravimetric analysis (TGA) on a Mettler Toledo TGA/SDTA 851e unit in a temperature range of $30-600^{\circ} \mathrm{C}$ at a heating rate of $10^{\circ} \mathrm{C} \mathrm{min}^{-1}$.

\section{RESULTS AND DISCUSSION}

\section{Preparation of Nanofibers and Their Modification by RIG}

The synthesis of s-PP nanofibrous sheets was carried out. Further, independent parameters of the electrospinning process including applied voltage, needle tip to collector distance (TCD) and flow rate were varied based on the combinations offered by BoxBehnken design (BBD) of RSM, as reported previously (Abbasi et al., 2018). Nanofibers with an average fiber diameter of $439 \mathrm{~nm}$ were obtained and used for grafting and amination due to their proper production rate and excellent fiber quality.

After being irradiated with an electron beam under different grafting parameters, the s-PP nanofibrous sheets were grafted with GMA. The effect of four main parameters, such as monomer concentration, absorbed dose, grafting time, and temperature on the DG was studied. Results showed a high dependency of the DG on reaction parameters, as reported elsewhere (Abbasi et al., 2018), and samples with DG in the range of $150-400 \%$ were obtained.

\section{Amination Parameters}

In this study, three different amines, including EA, DEA and TEA, were used for amination reactions. The effect of reaction parameters such as DG, amine concentration and reaction temperature on the degree of amination (DA) was studied.

The influence of reaction time on the degree of amination (DA) for samples with different DGs (150, 300, and 400\%) using EA, DEA, and TEA is shown in Figures $1 \mathbf{A}-\mathbf{C}$ where treatments with EA and DEA were performed under constant temperature and amine concentration of $60^{\circ} \mathrm{C}$ and $60 \mathrm{vol} \%$ in water, respectively. However, for TEA, a volume ratio of 50:50 $(\mathrm{v} / \mathrm{v})$ at $30^{\circ} \mathrm{C}$ was used. As for amination with EA (Figure 1A), the DA increased sharply, in the first $30 \mathrm{~min}$, for all samples with various DGs, showing a fast reaction rate in the initial stage of the amination. This was followed by a very slight increase that continued up to $120 \mathrm{~min}$ beyond which it reached a plateau. The maximum DA achieved for the sample with the DG of $150 \%$ was $98 \%$ whereas samples with DGs of 300 and $400 \%$ reached 94 and $90 \%$, respectively.

A similar trend was observed for amination using DEA. As can be seen in Figure 1B, the increase in reaction time led to an increase in DA for the three samples with various DGs. For the sample with $150 \%$ DG, DA sharply increased from $20 \%$ after $5 \mathrm{~min}$ to $98 \%$ after $60 \mathrm{~min}$ in an almost linear trend, indicating a high reaction rate at this stage. Subsequently, as time went by, DA reached a plateau. For samples with 300 and 400\% DGs, a sharp linear increase in DA was observed as time increased from 5 to $30 \mathrm{~min}$, reaching values of 65 and $58 \%$, respectively. This was followed by a slight increase in DA up to $120 \mathrm{~min}$ beyond which 

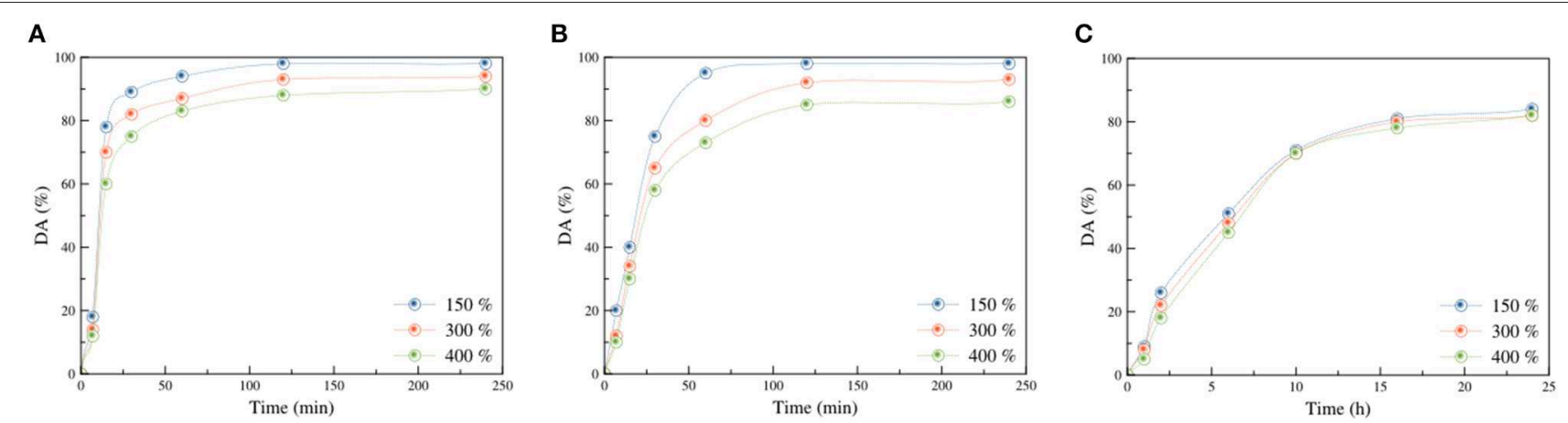

FIGURE 1 | Influence of reaction time on the DA of poly(GMA) grafted s-PP samples using EA (A), DEA (B), and TEA (C).

a plateau was reached at $93 \%$ for DG of 300 and $86 \%$ for DG of $400 \%$. The decrease in DA observed during the amination with EA and DEA at higher DGs was mostly caused by the decrease in sample porosity by the increase in grafting density, as revealed by SEM images. Thus, diffusion of the amination solution slowed down and hampered access to epoxy groups, leading to lower DA.

BET analysis showed that with increasing the degree of grafting from 150 to $300 \%$, the total pore volume of the samples decreased from 0.009 to $0.006 \mathrm{~cm}^{3} / \mathrm{g}$. However, it is worth noting that these very low values are related to intra-fiber pores, revealing an almost solid, non-porous structure of single fibers. Inter-fiber porosity which is the main type of porosity for these samples are formed through overlapping fibers (Abbasi et al., 2018). Therefore, with increasing the fiber size, and bead size and number, this type of porosity is decreased.

As for the amination reaction using TEA, which was carried out at $30^{\circ} \mathrm{C}$ to avoid a drastic change in its mechanical characteristics, reaction rate was much lower compared to that of EA and DEA. During the initial $10 \mathrm{~h}$ of the reaction, Figure $1 \mathrm{C}$ showed a significant increase in DA from about $8-70 \%$ for all grafted samples with various DGs. Then, a slight increase in DA followed up to $16 \mathrm{~h}$ beyond which it reached a plateau. At about $80 \%$, DA remained constant. The trend was the same for all the samples with various DGs.

Figure 1 reveals that kinetics of the amination reaction using various amines was in the order of primary $>$ secondary $>$ tertiary. It could be attributed to the spatial hindrance of various amines having a different number of alkyl groups around the nitrogen atom. With increasing the number of alkyl groups covalently bound to the nitrogen atom in the molecular structure of the amines, the number of efficient collisions with epoxy rings decreases, leading to lower reaction kinetics.

Figure 2 displays the effect of temperature (Figure 2A) and amine concentration (Figure 2B) on the DA using EA and DEA. Regarding EA, the increase in temperature from 30 to $50^{\circ} \mathrm{C}$ led to an increase in DA from 76 to $95 \%$ beyond which it reached a plateau. Further increase in the temperature did not significantly affect the DA. Hence, optimal temperature for amination reaction was maintained at $50^{\circ} \mathrm{C}$. A similar trend was observed for amination using DEA, showing an increase in DA from $15 \%$ at $25^{\circ} \mathrm{C}$ to $98 \%$ at $70^{\circ} \mathrm{C}$. All reactions were carried out for $60 \mathrm{~min}$ using $50 \mathrm{vol} \%$ amine concentration in water. Increasing the reaction temperature not only enhanced the diffusion of the amine solution into the nanofibrous sheet but also provoked the ring opening reaction of the epoxy group of Poly-GMA grafted chains (Zhuang et al., 2013). Furthermore, the higher DA observed for amination using EA at lower temperatures was an indication of lower activation energy for EA amination reaction compared to that of DEA.

It was noted that increasing EA concentration from 20 to $100 \%$ in water resulted in a sharp rise in DA from 35 to $98 \%$. This was attributed to improved frequency of efficient collisions between amine molecules and epoxy groups due to increased concentration of the loaded amine groups. On the other hand, a different trend was observed for amination with DEA. For instance, an increase in DEA concentration from 20 to $50 \%$ led to an increase in DA from 50 to $98 \%$. However, a further increase in DEA concentration triggered a decrease in DA, reaching to $30 \%$ for $100 \%$ pure amine. This could be ascribed to the decrease in the diffusion of highly concentrated amine solutions into the nanofibrous sheets, leading to lower DA for higher concentrations. Thereafter, the reactions were carried out using 50\% amine concentration. Thus, considering the high DA achieved in most of the samples at $70^{\circ} \mathrm{C}$, it can be reasonable to assume that $100 \%$ amination had been achieved.

\section{Changes in Nanofibrous Adsorbents Morphological Properties}

Morphological changes of pristine electrospun s-PP nanofibers during grafting with GMA and then amination using EA has already been discussed (Abbasi et al., 2018, 2019). In Figure 3, the effect of amination reaction using DEA on the grafted sPP nanofibers can be seen. After amination, the average fiber diameter increased from $500 \mathrm{~nm}$ for the $300 \%$ grafted sample to 568,622 , and $686 \mathrm{~nm}$ for the samples with DA of 30,85 , and $93 \%$, respectively. Formation of a layer of amine groups wrapping around the grafted nanofibers could be the reason for this diameter increase (Zhuang et al., 2013). Besides, when DA increased, the number and size of the beads increased so that for the DA of $93 \%$, mostly beads mixed with some fibers were observed.

In Figure 4, SEM images of 300\% grafted s-PP nanofibers, before and after amination using TEA with DA of $22 \%$ (B), $50 \%(C)$, and $82 \%(D)$, can be seen. Again, when DA increased, 

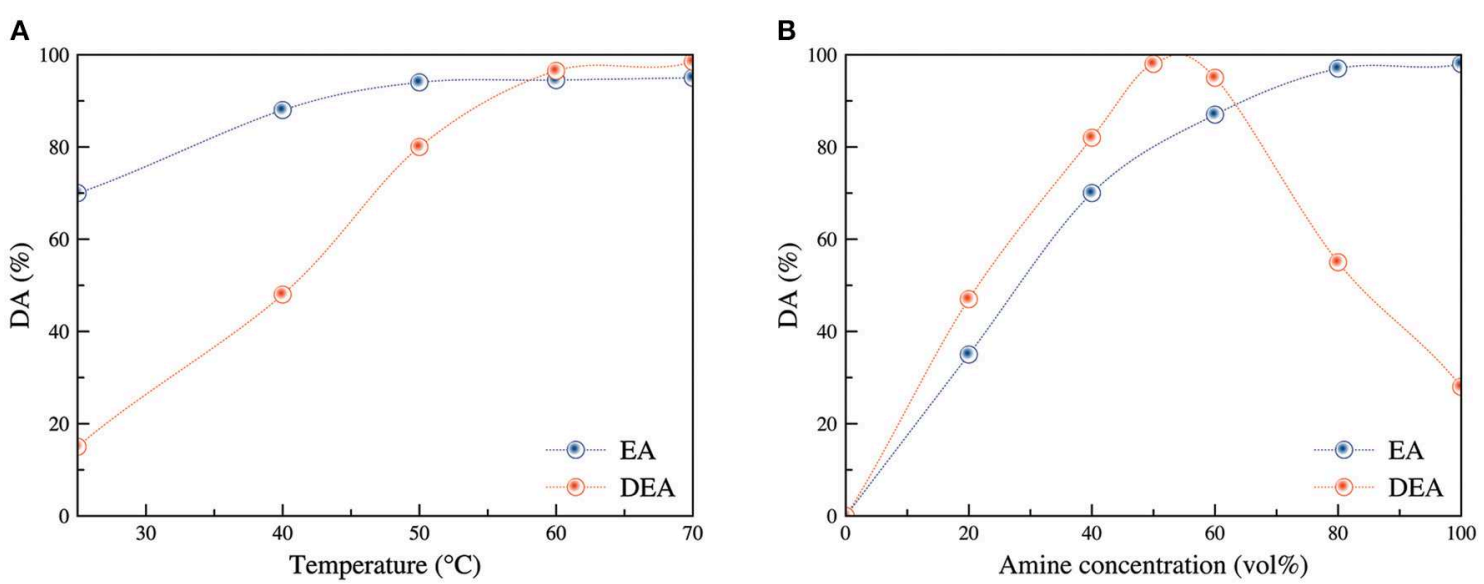

FIGURE 2 | Influence of reaction temperature (A) $\left(t=60 \mathrm{~min}\right.$ and $\mathrm{C}=50$ vol\%) and amine concentration $(\mathbf{B})\left(t=60 \mathrm{~min}\right.$ and $\left.T=60^{\circ} \mathrm{C}\right)$ on the DA of poly $(\mathrm{GMA})$ grafted S-PP samples using EA and DEA.
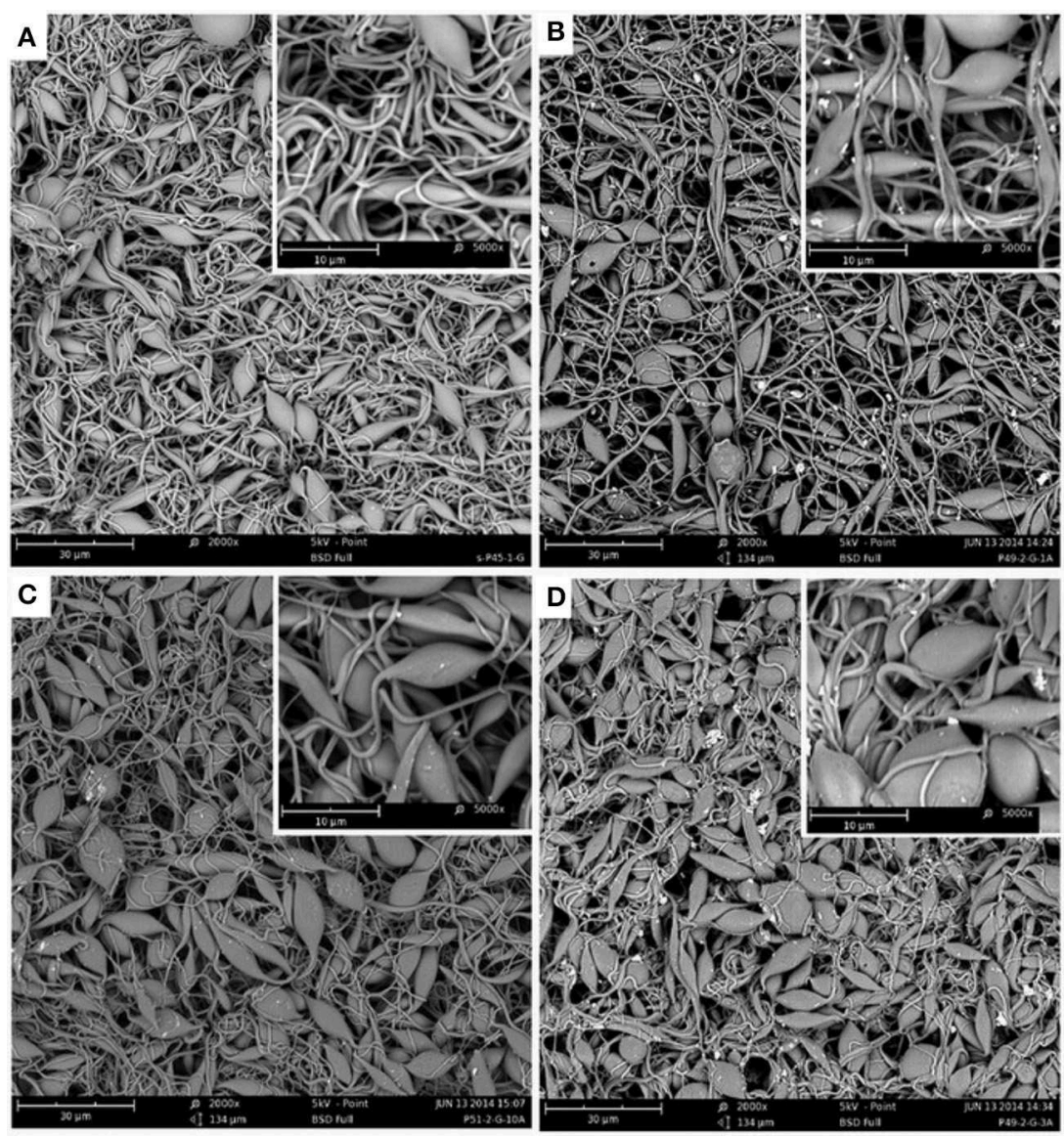

FIGURE 3 | SEM images of 300\% poly(GMA)-grafted nanofibers (A) and nanofibers aminated with DEA with DA of 30\% (B), $85 \%$ (C), and $93 \%$ (D) with magnification of 2,000 and 5,000 (inset).

fiber diameter increased from $500 \mathrm{~nm}$ for a grafted sample to 608,644 , and $742 \mathrm{~nm}$ for 22,50 , and $82 \%$ DA, respectively. The increase in size can be ascribed to the sheathing effect of amine groups on the grafted samples (Zhuang et al., 2013).
Furthermore, when DA increased, the majority of the fibers in the structure became swollen and made bead-like moieties in the fibers. These morphological and size changes in the poly(GMA) grafted s-PP nanofibers confirm the successful immobilization 

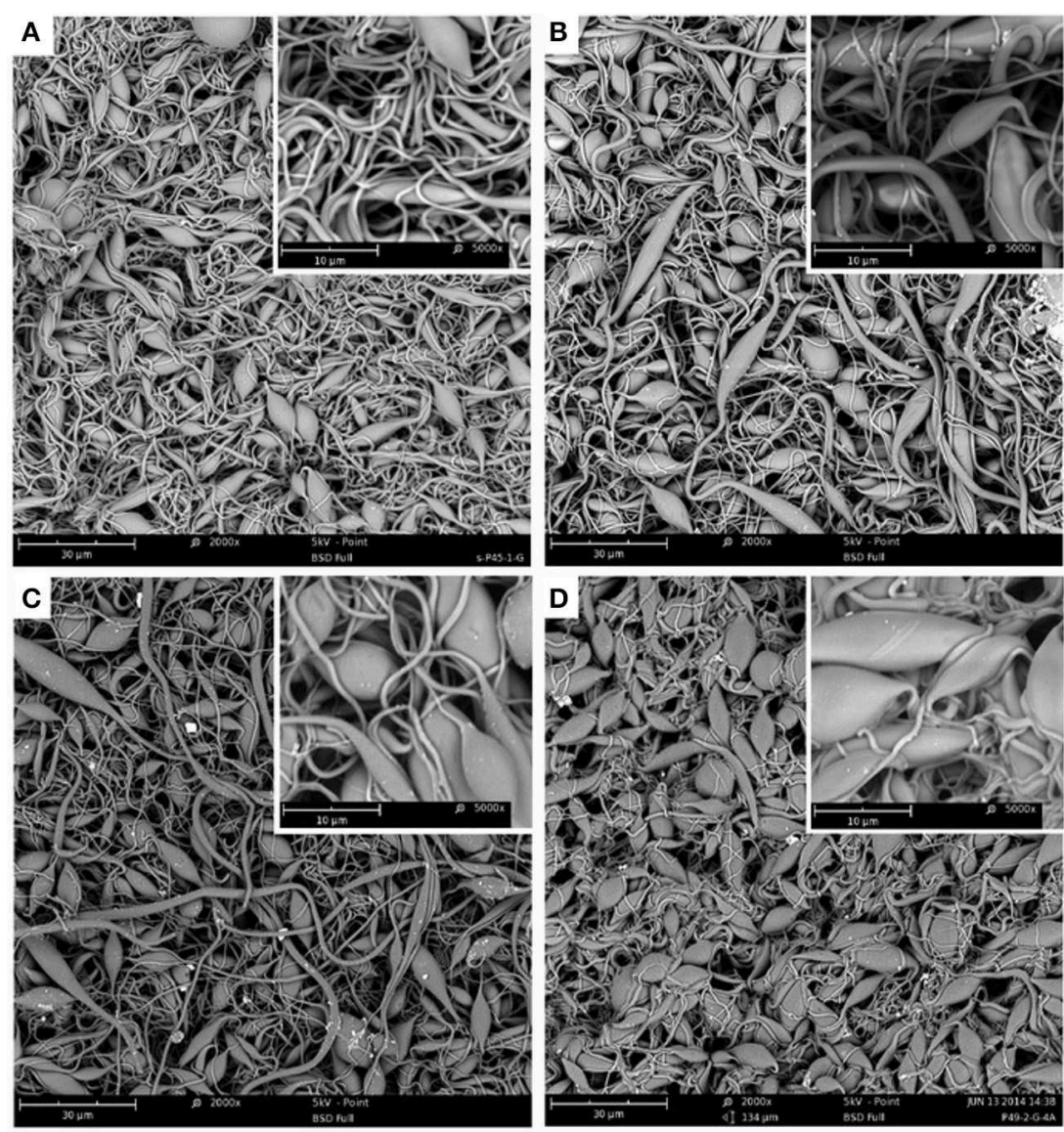

FIGURE 4 | SEM images of 300\% poly(GMA)-grafted nanofibers (A) and nanofibers aminated with TEA with DA of 22\% (B), 50\% (C), and $82 \%$ (D) with magnification of 2,000 and 5,000 (inset).

of the three various types of amine-containing groups in the obtained three adsorbents.

The specific surface area for defect-free nanofibrous mats with an average fiber diameter of around $500 \mathrm{~nm}$ was reported to be $\sim 5 \mathrm{~m}^{2} / \mathrm{g}$ (Schreuder-Gibson et al., 2002). For the s-PP nanofibers prepared in this study, the surface area was around $2 \mathrm{~m}^{2} / \mathrm{g}$, which could be attributed to the presence of irregularities and large beads formed during electrospinning process. Even though the obtained specific surface area is higher than that of commercial non-woven microfibers in size range of 5-20 $\mu \mathrm{m}$ (between 0.1 and $0.5 \mathrm{~m}^{2} / \mathrm{g}$ ) (Schreuder-Gibson et al., 2002), which was the main point of using nanofibers instead of microfibers, presence of beads and non-continuous fibers in the prepared samples leads to decreased surface area in comparison with the ideal fibers, potentially decreasing the adsorption capacity and efficiency. However, it has been shown that the presence of beads on the nanofibrous structure leads to a lower pressure drop in air filtration applications. These microbeads act like a spacer and by changing the internal structure of nanofibrous mat and increasing the distance between fibers, modify the fiber packing density, leading to lower pressure drop (Yun et al., 2010; Wang et al., 2015). Therefore, even though the formation of beads on electrospun nanofibers was unavoidable due to the low solubility of PP in the used solvent mixture, it could potentially be beneficial from the viewpoint of pressure drop in $\mathrm{CO}_{2}$ adsorption.

\section{Chemical Composition}

As can be seen in Figure 5, successful grafting and amination reactions using three various amines of EA, DEA, and TEA was confirmed by FTIR spectroscopy. After grafting, new absorption bands appeared at $1,725,1,255,905$, and $845 \mathrm{~cm}^{-1}$. The strong band at $1,725 \mathrm{~cm}^{-1}$ and the weak broad band at $1,255 \mathrm{~cm}^{-1}$ are attributed to $-\mathrm{C}=\mathrm{O}$ and $\mathrm{C}-\mathrm{O}$ - stretching of acrylate, respectively (Choi et al., 2001). The two small peaks at 905 and $845 \mathrm{~cm}^{-1}$ are characteristic bands of the epoxy ring (Bondar et al., 2004; Zhuang et al., 2013; Mahmoud Nasef et al., 2014). It was observed that there was no significant change in the position and intensity of the carbonyl band of poly(GMA) at $1,725 \mathrm{~cm}^{-1}$ during the amination reaction with EA, DEA, and TEA (Insert in Figure 5). On the other hand, the characteristic bands of the epoxy ring at 905 and $845 \mathrm{~cm}^{-1}$ almost disappeared during the amination reactions. Besides, a new broad band, attributed to the O-H stretch, appeared at $3,500-3,000 \mathrm{~cm}^{-1}$, which was due to the addition of hydroxyl group to the structure. Aliphatic 


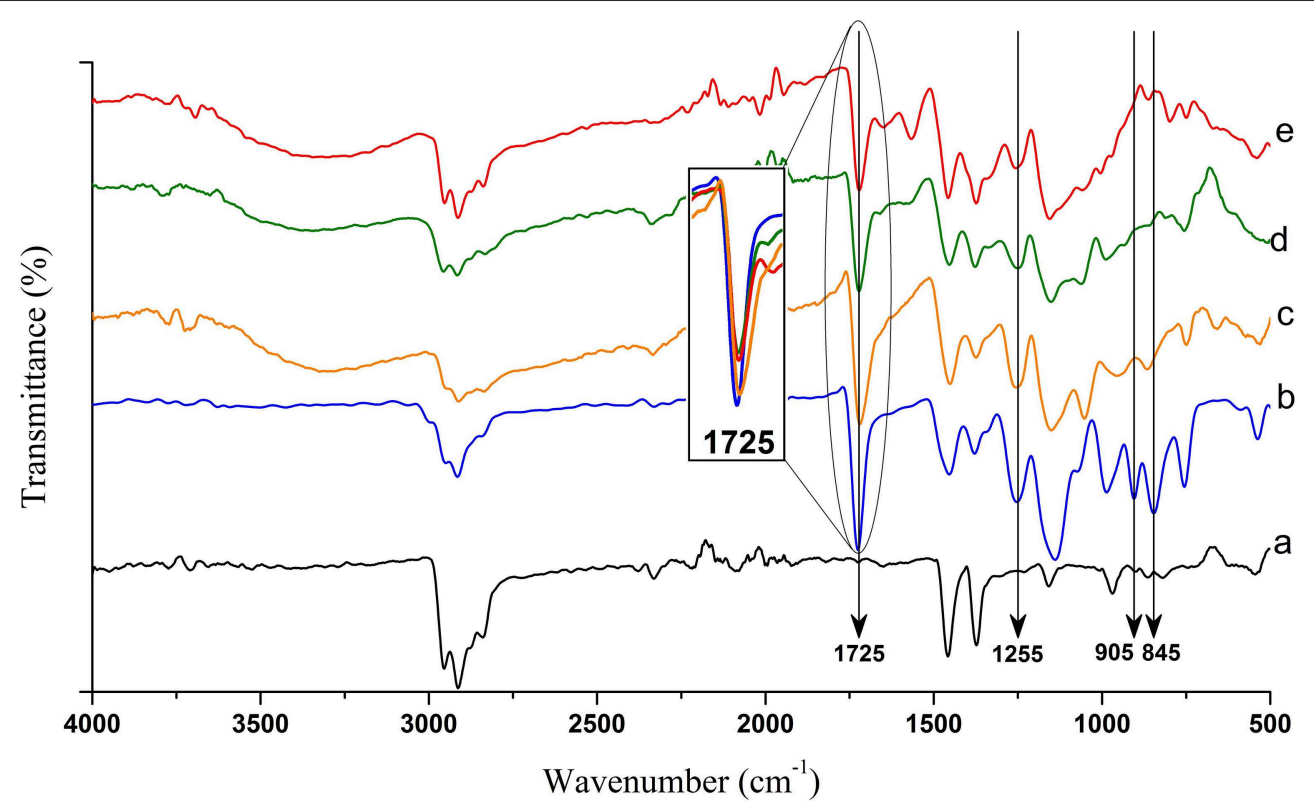

FIGURE 5 | FTIR spectra of pristine s-PP nanofibers (a) compared with 300\% grafted nanofibers (b) and fibers aminated with EA (c), DEA (d), and TEA (e).

amines also showed a C-N stretching vibration at 1,250-1,020 $\mathrm{cm}^{-1}$. Nevertheless, several characteristic peaks of the s-PP made this area highly crowded leading to the obscuring of the C$\mathrm{N}$ peak. These results further validated the effective amination of the grafted samples through opening the epoxy rings of the grafted poly(GMA).

\section{Thermal Properties}

In Figure 6, DSC thermograms of pristine, poly(GMA)-grafted and aminated nanofibers using various amines can be seen. The melting point of pristine s-PP appeared at about $124^{\circ} \mathrm{C}$ as an endothermic peak. As for the grafted nanofibers, this peak was very weak. The graph showed an additional broad peak at $227^{\circ} \mathrm{C}$ which can be attributed to the first stage decomposition of poly(GMA) side chains. Regarding all the aminated samples, a small peak was observed between 120 and $130^{\circ} \mathrm{C}$ which was ascribed to the moisture adsorbed onto the aminated films, showing the hydrophilicity of the samples (Choi et al., 2001).

Figure 7 depicts TGA thermograms of pristine, GMA-grafted and EA-, DEA-, and TEA-aminated s-PP nanofibers. As for pristine s-PP, a single step degradation was observed at $461^{\circ} \mathrm{C}$ due to the main polymeric backbone thermal decomposition. The GMA-grafted sample showed three-stage decomposition behavior. Degradation of glycidyl and carboxyl groups of GMA side chains appeared at 228 and $313^{\circ} \mathrm{C}$, respectively (Choi et al., 2015). Like the pristine nanofibers, the final decomposition stage at $455^{\circ} \mathrm{C}$ was for the thermal decomposition of the main sPP backbone.

As for EA-aminated samples, a three-stage decomposition pattern was observed. The first weight loss was because of the moisture adsorbed on the aminated samples, showing the hydrophilic nature of the sheets after amination (Choi et al.,
2015). Again, the decomposition peak of GMA side chains disappeared which confirmed the successful amination reaction. Further, the carboxyl decomposition peak shifted to $333^{\circ} \mathrm{C}$, and a new peak attributed to the degradation of aminated species appeared at $417^{\circ} \mathrm{C}$. The decomposition peak of polymeric backbone also appeared at $465^{\circ} \mathrm{C}$. Thus, the thermal stability of GMA-grafted samples improved after amination with EA. This can be explained by the opening of unstable epoxy rings, leading to the removal of the stress of three-membered epoxy ring. As a result, the thermal stability of the sample improved.

After amination of poly(GMA)-grafted samples with DEA, a new peak appeared at around $434^{\circ} \mathrm{C}$. This was attributed to the degradation of the aminated species. Further, the degradation peak of GMA side chains disappeared, and the peak related to the carboxyl group shifted to $291^{\circ} \mathrm{C}$. The decomposition peak of polymeric backbone was observed at $460^{\circ} \mathrm{C}$. Like the EAaminated sample, the first weight loss was for the removal of absorbed moisture from the adsorbent. Here as well, the thermal stability of the sample improved after amination with DEA due to the ring-opening reaction on unstable epoxy rings.

Like the other two aminated samples, the first weight loss of TEA-aminated adsorbent was due to adsorbed moisture. Furthermore, the thermogram showed a new amine-moiety related decomposition peak at $417^{\circ} \mathrm{C}$ which merged with the decomposition peak of the main s-PP backbone. Since the amination reaction yield was only $82 \%$, some of the epoxy rings were left in the structure. Hence, the related decomposition peak shifted to a lower temperature of $210^{\circ} \mathrm{C}$. This shift could be due to the spatial hindrance of big TMA molecules, making epoxy rings even more unstable. As a result, the TEA aminated samples showed lower thermal stability compared to the EA- and DEAaminated adsorbents, as well as the GMA-grafted sample. 


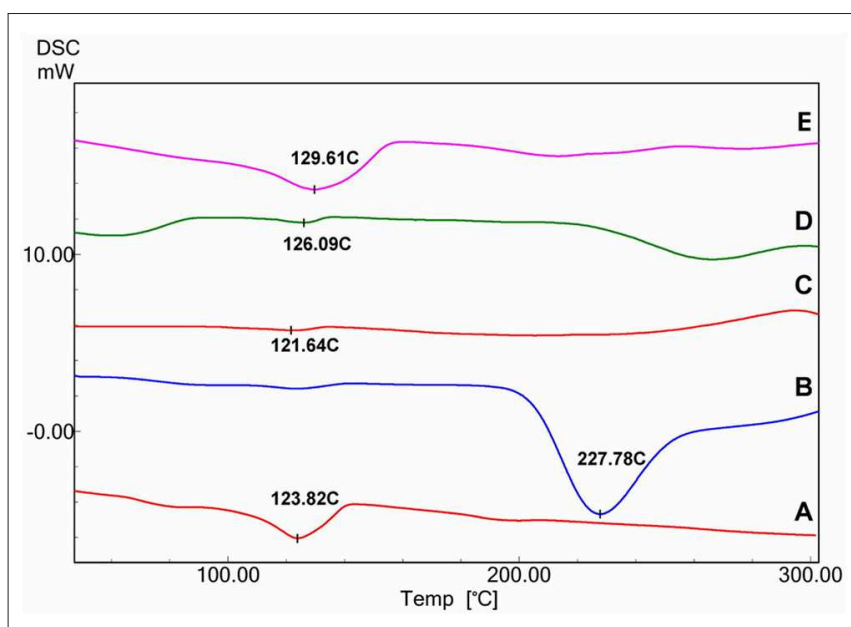

FIGURE 6 | DSC thermograms of pristine nanofibers (A), 300\% poly(GMA) grafted nanofibers (B) and EA (C), DEA (D), and TEA (E) aminated nanofibers.

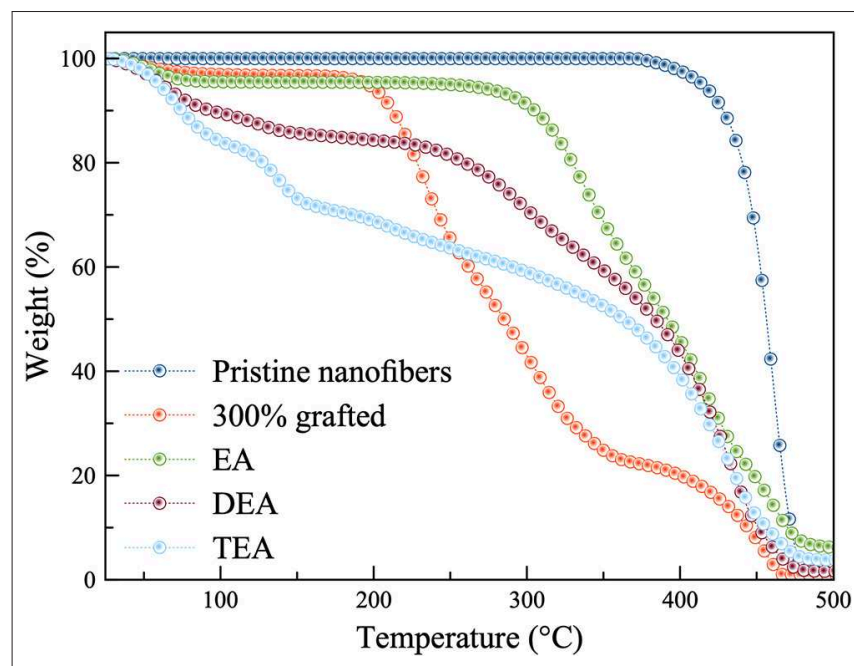

FIGURE 7 | TGA of pristine, poly(GMA) grafted, EA, DEA, and TEA aminated s-PP nanofibers.

\section{$\mathrm{CO}_{2}$ Adsorption}

Figure 8 shows $\mathrm{CO}_{2}$ adsorption breakthrough curves for s-PP nanofibers grafted by GMA and aminated using EA, DEA, and TEA. Temperature, degree of grafting of the samples and feed concentration was changed in the range of $30-50^{\circ} \mathrm{C}, 150-400$, and $5-15 \%$ to study their effect on adsorption capacity. In Table 1, the results of $\mathrm{CO}_{2}$ adsorption tests are summarized for all nanofibrous s-PP adsorbents grafted by poly(GMA) and aminated using three various amines.

As for the EA-aminated adsorbents, when adsorption temperature increased from 30 to 40 and $50^{\circ} \mathrm{C}$, the breakthrough curve shifted to shorter times and the adsorption capacity decreased from 2.57 to 1.67 , and $1.04 \mathrm{mmol} \mathrm{CO}_{2} / \mathrm{g}$ of the adsorbent, respectively. A similar trend was observed for DEAand TEA- aminated adsorbents. The adsorption capacity of the DEA-aminated sample decreased from 1.78 for $30^{\circ} \mathrm{C}$ to 1.49 and $1.18 \mathrm{mmol} \mathrm{CO}_{2} / \mathrm{g}$ of the adsorbent for 40 and $50^{\circ} \mathrm{C}$, respectively.
Again, the TEA-aminated adsorbent showed a decrease in its adsorption capacity from 0.8 to 0.68 and 0.42 for 30 to 40 and $50^{\circ} \mathrm{C}$, respectively. For all three types of the synthesized adsorbents, the entropy change and the heat of adsorption proved negative for $\mathrm{CO}_{2}$ adsorption. Hence, it is evident that when the temperature increased, adsorption capacity decreased (Drese, 2010).

Three samples with various DGs of 150,300 , and $400 \%$ with maximum DA obtained for each sample was used to investigate the influence of DG/DA combination (determining amine density) on the $\mathrm{CO}_{2}$ adsorption capacity of various synthesized adsorbents. The increase in DG led to a rise in the number of epoxy rings on the sample for the amination reaction. As a result, it was expected to have higher amine density for higher DG and therefore, higher adsorption capacity. On the other hand, when DG increased, the highest DA that was obtained for the sample decreased.

When DG increased for the EA-aminated adsorbents in the order of 150,300 and $400 \%$, the highest DA that was determined dropped from 98 to 94 and 90\%, respectively. Thus, for the samples with DGs of 150, 300 and 400\%, amine density rose in the order of $3.30,3.81$, and $3.87 \mathrm{mmol} / \mathrm{g}$ respectively. Besides, amine efficiency for the EA-aminated samples with DG of 150,300 , and $400 \%$ was found to be $68.5,67.5$, and $59 \%$, respectively. Essentially, a combination of amine density and amine efficiency of an adsorbent determines its adsorption capacity. Consequently, the highest adsorption capacity $(q)$ of $2.57 \mathrm{mmol} \mathrm{CO}_{2} / \mathrm{g}$ of the adsorbent was obtained for EA-aminated samples having DG of 300\%. For the samples with DG of 150 and $400 \%$, the adsorption capacity proved to be 2.26 and $2.28 \mathrm{mmol}$ $\mathrm{CO}_{2} / \mathrm{g}$ of the adsorbent, respectively.

The EA-aminated sample with DG of $300 \%$ had about $15 \%$ higher amine density compared with the sample having DG of $150 \%$. This led to $14 \%$ higher adsorption capacity which produced almost the same amine efficiency for the two samples. On the other hand, although the amine density of the sample with DG of $400 \%$ was a little bit higher than that of the sample with DG of $300 \%$, both adsorption capacity and amine efficiency were seen to be lower. This demonstrated, therefore, high pore blockage of the adsorbent and less access of $\mathrm{CO}_{2}$ molecules to amine groups.

As for DEA-aminated adsorbents, when DG increased from 150 to 300 and $400 \%$, the highest DA decreased from 98 to 93 and $86 \%$, respectively. As a result, the amine density of the sample with DG of $300 \%(3.61 \mathrm{mmol} / \mathrm{g}$ ) was higher than that of the samples with DG of $150 \%(2.18 \mathrm{mmol} / \mathrm{g})$ and $400 \%(3.57$ $\mathrm{mmol} / \mathrm{g})$. On the other hand, amine efficiency for DEA-aminated samples was $50.6,49.3$, and $42.5 \%$ for 150,300 , and $400 \%$ DG, respectively. The combination of amine density and amine efficiency revealed the adsorption capacity for these samples to be $1.61,1.78$, and $1.52 \mathrm{mmol} \mathrm{CO}_{2}$ per gram of adsorbent, respectively. As can be seen, the highest adsorption capacity was for the sample with 300\% DG, followed by 150 and 400\%. Even though the amine density of the sample with DG of $400 \%$ was higher than that of the sample with DG of $150 \%$, because of pore blockage and less accessibility of amine functional groups to $\mathrm{CO}_{2}$ molecules, its adsorption capacity was lower. 

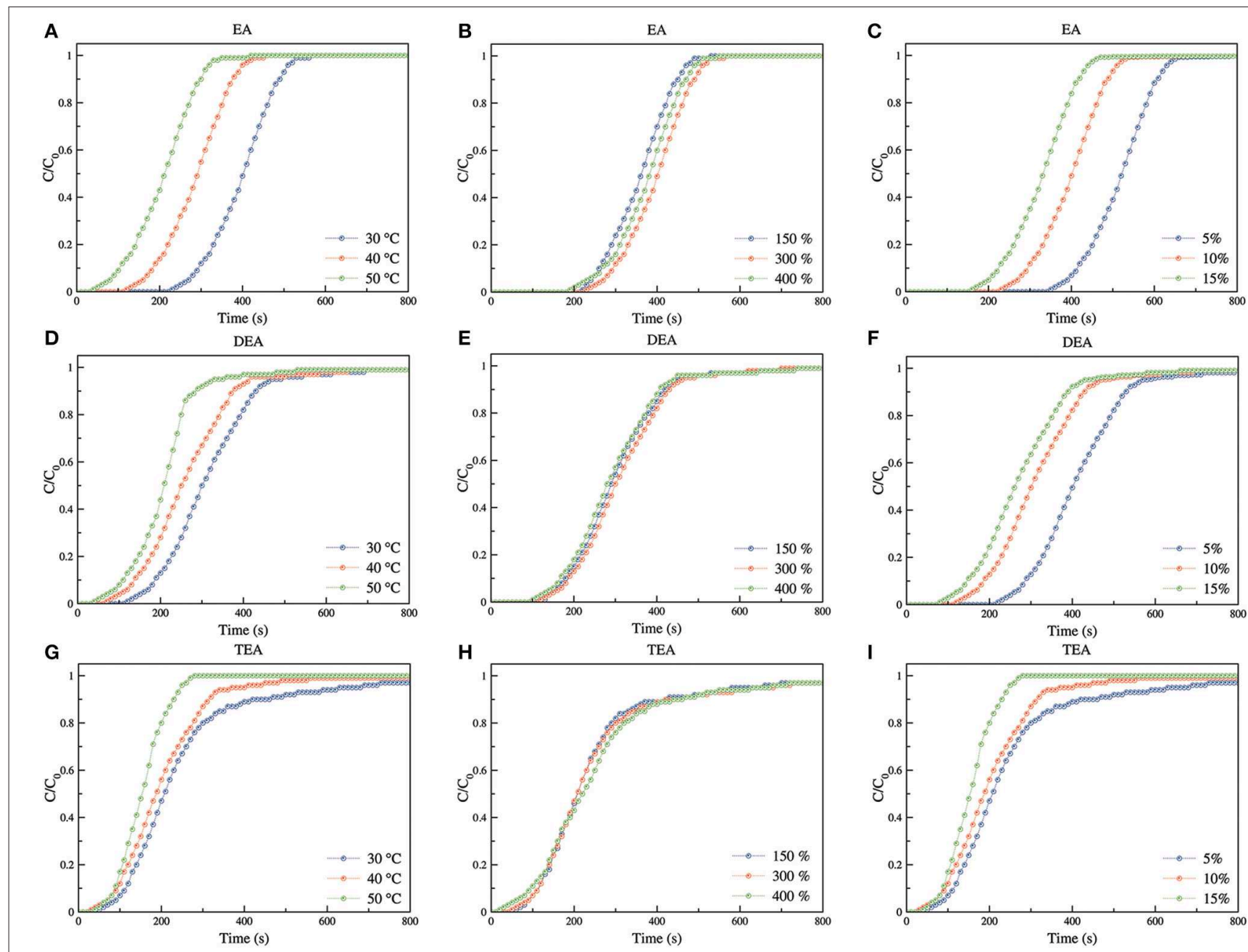

FIGURE 8 | $\mathrm{CO}_{2}$ adsorption breakthrough curves for EA (A-C), DEA (D-F), and TEA (G-I) aminated samples at different temperatures $(\mathbf{A}, \mathbf{D}, \mathbf{G})(\mathbf{C}=10 \%$; DG $=$ $300 \%$; $D A=94 \%)$, various DG/amine density $(\mathbf{B}, \mathbf{E}, \mathbf{H})\left(C=10 \% ; \mathrm{T}=30^{\circ} \mathrm{C}\right)$, and different feed concentration $(\mathbf{C}, \mathbf{F}, \mathbf{I})\left(\mathrm{DG}=300 \% ; \mathrm{DA}=94 \% ; \mathrm{T}=30^{\circ} \mathrm{C}\right)$.

When DG increased from 150 to 300\% for the TEA-aminated samples, the highest DA decreased only by $2 \%$ from 84 to $82 \%$. In this regard, there was no difference between the samples with the DG of 300 and $400 \%$. As a result, the amine density of the samples increased when DG increased, reaching to 2.61, 3.01 , and $3.14 \mathrm{mmol} / \mathrm{g}$ for 150,300 , and $400 \%$, respectively. However, TEA-aminated samples showed amine efficiencies of $28.9,26.6$, and $26.8 \%$ for 150,300 , and $400 \%$ DG, respectively. The combination of both amine density and efficiency resulted in adsorption capacities of $0.75,0.80$, and $0.84 \mathrm{mmol} \mathrm{CO}_{2}$ per gram of adsorbent, respectively. Thus, it can be observed that DG did not have a strong influence on adsorption capacity of the TEAaminated samples. Although the amine density of the samples with higher DGs were higher, the decrease in amine efficiency due to pore blockage and less accessibility of $\mathrm{CO}_{2}$ molecules to amine functional groups compensated for the higher amine density; almost similar adsorption capacities were achieved for all three adsorbents.
Figure 8C shows the effect of feed concentration on the breakthrough curves of $\mathrm{CO}_{2}$ adsorption. Consequently, when feed concentration increased, breakthrough point was reached in a shorter time and the curve shifted to the left. As for higher concentrations, shorter times were required to reach equilibrium point, and the adsorption kinetics was faster. Furthermore, adsorption capacity and amine efficiency also changed when feed concentration was modified.

As for EA-aminated adsorbents, when feed concentration increased from 5 to $15 \%$, amine efficiency also increased from 49.8 to $75.3 \%$. A similar rise in adsorption capacity from 1.90 to $2.87 \mathrm{mmol} \mathrm{CO} / \mathrm{g}$ of the adsorbent was observed. As for the DEA-aminated samples, amine efficiency and adsorption capacity increased from 41.3 to $57.1 \%$ and from 1.49 to 2.06 $\mathrm{mmol} \mathrm{CO}_{2} / \mathrm{g}$ adsorbent, respectively, when feed concentration increased in the range of 5-15\%. The TEA aminated samples also showed a comparable trend. When feed concentration increased from 5 to $15 \%$, amine efficiency and adsorption capacity also 
TABLE 1 | Comparison between the adsorption capacities of aminated adsorbents.

\begin{tabular}{lllllll}
\hline $\mathrm{C}_{0}(\%)$ & $\mathrm{T}\left({ }^{\circ} \mathrm{C}\right)$ & $\mathrm{DG}(\%)$ & $\mathrm{DA}(\%)$ & $\begin{array}{c}\text { Amine } \\
\text { density } \\
(\mathrm{mmol} / \mathrm{g})\end{array}$ & $\begin{array}{c}\text { Amine } \\
\text { efficiency }(\%)\end{array}$ & $\begin{array}{c}\mathrm{q} \\
(\mathrm{mmol} / \mathrm{g})\end{array}$
\end{tabular}

\begin{tabular}{|c|c|c|c|c|c|c|}
\hline \multicolumn{7}{|l|}{ EA } \\
\hline 10 & 30 & 300 & 94 & 3.81 & 67.5 & 2.57 \\
\hline 10 & 40 & 300 & 94 & 3.81 & 43.8 & 1.67 \\
\hline 10 & 50 & 300 & 94 & 3.81 & 27.3 & 1.04 \\
\hline 10 & 30 & 150 & 98 & 3.30 & 68.5 & 2.26 \\
\hline 10 & 30 & 400 & 90 & 3.87 & 59.0 & 2.28 \\
\hline 5 & 30 & 300 & 94 & 3.81 & 49.8 & 1.90 \\
\hline 15 & 30 & 300 & 94 & 3.81 & 75.3 & 2.87 \\
\hline \multicolumn{7}{|c|}{ DEA } \\
\hline 10 & 30 & 300 & 93 & 3.61 & 49.3 & 1.78 \\
\hline 10 & 40 & 300 & 93 & 3.61 & 41.3 & 1.49 \\
\hline 10 & 50 & 300 & 93 & 3.61 & 32.6 & 1.18 \\
\hline 10 & 30 & 150 & 98 & 2.18 & 50.6 & 1.61 \\
\hline 10 & 30 & 400 & 86 & 3.57 & 42.5 & 1.54 \\
\hline 5 & 30 & 300 & 93 & 3.61 & 41.3 & 1.49 \\
\hline 15 & 30 & 300 & 93 & 3.61 & 57.1 & 2.06 \\
\hline \multicolumn{7}{|c|}{ TEA } \\
\hline 10 & 30 & 300 & 82 & 3.01 & 26.6 & 0.80 \\
\hline 10 & 40 & 300 & 82 & 3.01 & 22.4 & 0.68 \\
\hline 10 & 50 & 300 & 82 & 3.01 & 14.0 & 0.42 \\
\hline 10 & 30 & 150 & 84 & 2.61 & 28.9 & 0.75 \\
\hline 10 & 30 & 400 & 82 & 3.14 & 26.8 & 0.84 \\
\hline 5 & 30 & 300 & 82 & 3.01 & 20.4 & 0.61 \\
\hline 15 & 30 & 300 & 82 & 3.01 & 31.1 & 0.94 \\
\hline
\end{tabular}

increased from 20.4 to $31.1 \%$ and from 0.61 to $0.94 \mathrm{mmol} \mathrm{CO}_{2} / \mathrm{g}$ adsorbent, respectively.

The highest adsorption capacities for the EA-, DEA- and TEAaminated samples were $2.87,2.06$, and $0.94 \mathrm{mmol} / \mathrm{g}$, obtained for the adsorbents with DG of $300 \%, \mathrm{CO}_{2}$ concentration of $15 \%$, and DA of 94,93 , and $82 \%$, respectively. Further, the highest amine efficiency for EA-, DEA-, and TEA- aminated samples were 75, 57 , and $31 \%$ respectively. Therefore, high adsorption capacities are expected for these adsorbents. However, their capacities are considered to be moderate mostly due to the high weight percentage of s-PP base polymer which does not participate in the adsorption process.

Amine efficiency for EA-aminated sample was higher than the values previously reported for other amine-containing $\mathrm{CO}_{2}$ adsorbents, namely Aziridine grafted SBA-15 (44\%) (Hicks et al., 2008), PEI-modified glass microfibers (54\%) (Li et al., 2008), amine-based Nano-fibrillated cellulose (28\%) (Gebald et al., 2011), triethylenetetramine-bearing polypropylene microfibers (46\%) (Zhuang et al., 2013), and (DAEAPTS)-grafted SBA-15 (23\%) (Mittal et al., 2015).

When the $\mathrm{CO}_{2}$ adsorption capacity of EA-, DEA-, and TEAcontaining samples is compared, it was observed that capacity decreased in the order of primary $>$ secondary $>$ tertiary amines.
This effect has already been reported in previous studies (Ko et al., 2011) showing the effect of amine chemical structure on its ability to attach to $\mathrm{CO}_{2}$ molecules. A primary amine is attached to only one alkyl group and two hydrogen atoms. Since the molecule is smaller, the spatial hindrance is minimum for attaching to $\mathrm{CO}_{2}$ molecules. Secondary and tertiary amines are attached to two and three alkyl groups, respectively. So, the size of various types of amines increases according to amine type and the number of alkyl groups attached to the nitrogen atom. This increase in size results in higher spatial hindrance and less chance of $\mathrm{CO}_{2}$ molecules getting close to the nitrogen atom to form a covalent bonding. As a result, primary amines have higher affinity to $\mathrm{CO}_{2}$ molecules as well as higher adsorption capacity. Secondary and tertiary amines are ranked second and third.

\section{Regeneration}

For real world applications, regeneration performance is one of the crucial characteristics of an adsorbent. In Figure 9, breakthrough curves (a) and $\mathrm{CO}_{2}$ adsorption capacities (b) on fresh and regenerated EA-, DEA-, and TEA-aminated samples at each regeneration cycle can be seen. Hence, all types of adsorbents show high stability against regeneration process. Consequently, after four regeneration cycles, the adsorption capacity of the EA-aminated samples decreased from 2.57 to $2.35 \mathrm{mmol} / \mathrm{g}$, showing an 8\% decrease in capacity. Most of this decrease happened during the first and second regeneration cycles, after which the capacity remained almost constant.

For the adsorbents containing DEA, excellent stability was observed. After four cycles of regeneration, a 13\% drop in adsorption capacity happened. Thus, capacity decreased from 1.78 to $1.55 \mathrm{mmol} / \mathrm{g}$. The stability of the DEA containing adsorbent was less than that of the EA and TEA containing samples. The TEA aminated samples demonstrated excellent regeneration performance. Even after four cycles of regeneration, the adsorption capacity practically did not change and remained at around $0.80 \mathrm{mmol} / \mathrm{g}$. This indicated very high stability of the samples containing TEA against thermal treatment during the regeneration process. FTIR spectroscopy on the amine-bearing adsorbents after 4 cycles of regeneration showed no considerable change in their chemical structure, confirming their stability during the regeneration process.

It is worth noting that the regeneration process was performed at $80^{\circ} \mathrm{C}$ for $15 \mathrm{~min}$, which is considered as low temperature and short time compared to the regeneration process of other amine-bearing $\mathrm{CO}_{2}$ adsorbents. For example, regeneration temperature/time of some of the adsorbents reported in the literature was: $105^{\circ} \mathrm{C} / 40 \mathrm{~min}$ for PEI-containing polyamide6 (Zainab et al., 2017), $130^{\circ} \mathrm{C} / 180 \mathrm{~min}$ for Aziridine grafted SBA-15 (Hicks et al., 2008), $120^{\circ} \mathrm{C} / 30 \mathrm{~min}$ for PEI-modified glass microfibers ( $\mathrm{Li}$ et al., 2008) and benzyl amine-bearing ion exchange resin (Alesi and Kitchin, 2012), $90^{\circ} \mathrm{C} / 60 \mathrm{~min}$ for amine-based Nano-fibrillated cellulose (Gebald et al., 2011), and $100^{\circ} \mathrm{C} / 20 \mathrm{~min}$ for triethylenetetramine-bearing polypropylene microfibers (Zhuang et al., 2013). It decreases energy and time requirements for the regeneration process, making the new materials more viable for industrial applications. 


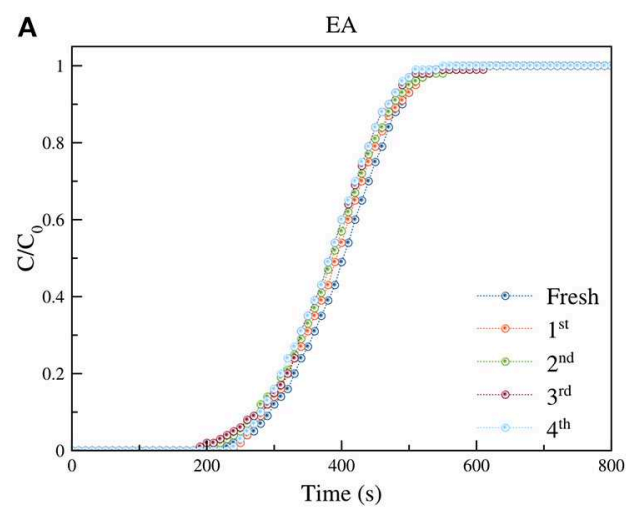

C

DEA

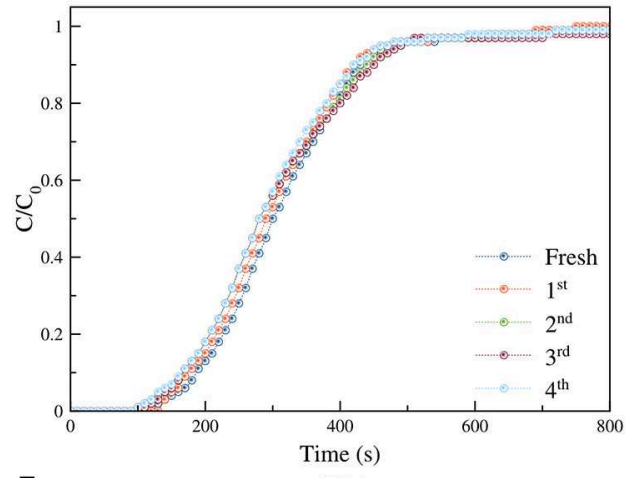

E

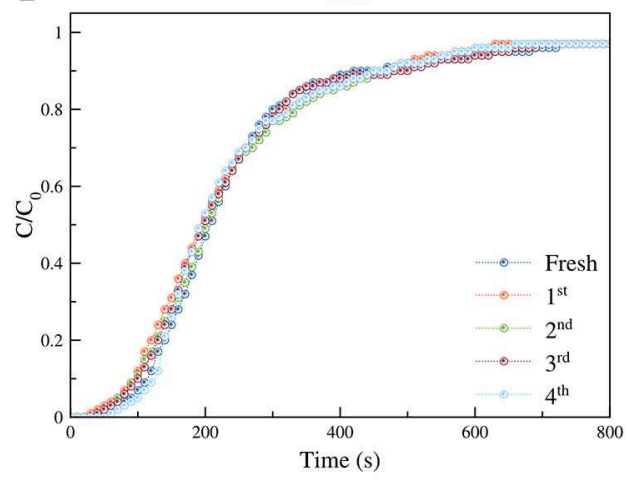

B

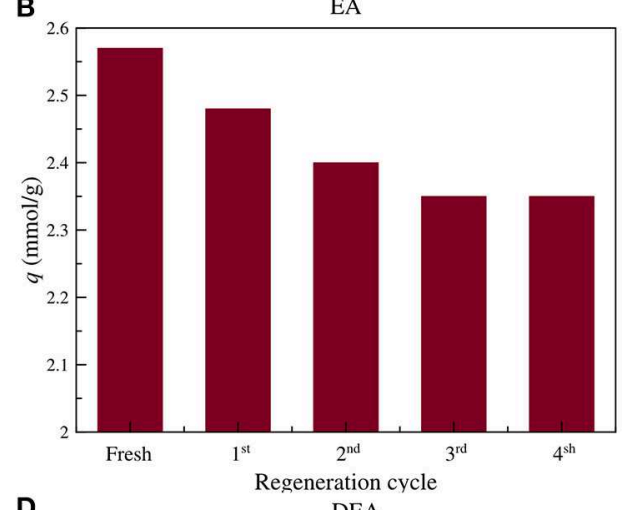

DEA

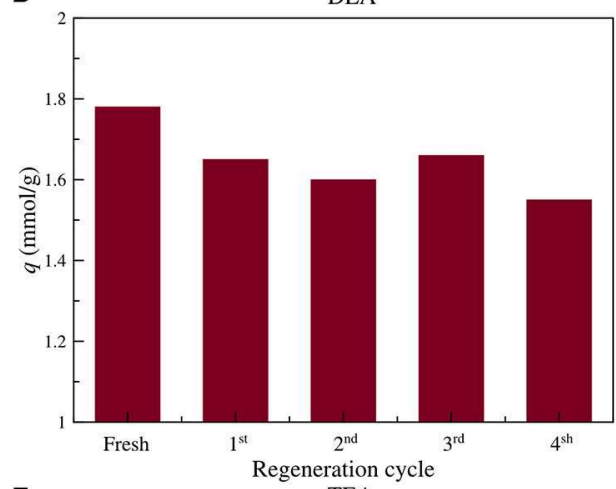

TEA

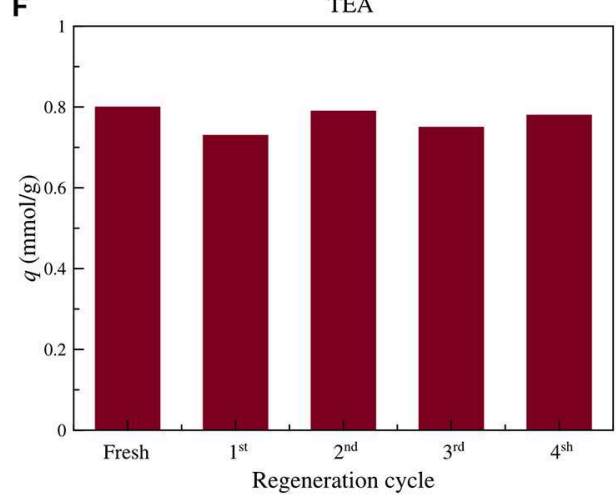

FIGURE 9 | Breakthrough curves of $\mathrm{CO}_{2}$ adsorption on fresh and regenerated adsorbents (A,C,E) and $\mathrm{CO}_{2}$ adsorption capacities (B,D,F) at each regeneration cycle $(\mathrm{C}=10 \% ; \mathrm{P}=1$ bar and flow rate $=50 \mathrm{ml} / \mathrm{min})$ for EA (A,B), DEA (C,D), and TEA (E,F) aminated samples.

\section{CONCLUSION}

A series of amine-bearing electrospun s-PP nanofibrous $\mathrm{CO}_{2}$ adsorbents were successfully synthesized using a versatile 3 stage procedure: namely, electrospinning of s-PP to prepare pristine nanofibers, RIG of GMA onto electrospun nanofibers and amination of grafted nanofibers using EA, DEA and TEA aminating agents to introduce required amine functional groups for $\mathrm{CO}_{2}$ adsorption. Nanofibrous sheets with an average fiber diameter of $439 \mathrm{~nm}$ were obtained and grafted with poly(GMA) to DGs in the range of $150-400 \%$ by manipulating grafting parameters. The DA from different amines was found to be dependent on parameters such as DG, temperature, time and amine concentration. Interestingly, when DG increased, DA decreased despite having more poly(GMA) grafts. This trend was attributed to higher pore blockage limiting the access of amination agents to epoxy rings of grafted poly(GMA). The highest DA for EA-, DEA-, and TEA- aminated samples was 98, 98, and $84 \%$, respectively. The $\mathrm{CO}_{2}$ adsorption capacity of the adsorbents was studied in a fixed bed column under various parameters, including adsorption temperature, amine density and initial $\mathrm{CO}_{2}$ concentration. Results revealed an increasing order of primary $>$ secondary $>$ tertiary amines. Thus, it was noted that EA-, DEA- and TEA-aminated adsorbents showed $\mathrm{CO}_{2}$ adsorption capacity values of $2.87,2.06$, and $0.94 \mathrm{mmol} / \mathrm{g}$, respectively. Moreover, the highest capacity was 
obtained for the samples with DG of 300\% in all three types of adsorbents at an initial $\mathrm{CO}_{2}$ concentration of $15 \%$ at $30^{\circ} \mathrm{C}$. The amine efficiency of EA-, DEA-, and TEAaminated adsorbents was found to be 75,57 , and $31 \%$, respectively, showing very high efficiency for the amine functional groups. All types of adsorbents demonstrated high stability during the four cycles of the regeneration process at $80^{\circ} \mathrm{C}$, with the lowest capacity loss of $2.5 \%$ being for the TEA-aminated sample, followed by 8 and $13 \%$ for EA and DEA aminated adsorbents, respectively. The results of this study showed that radiation grafted and aminated polymeric nanofibrous sheets had strong potential to be used as efficient $\mathrm{CO}_{2}$ adsorbents.

\section{DATA AVAILABILITY STATEMENT}

All datasets generated for this study are included in the article/supplementary material.

\section{REFERENCES}

Abbasi, A., Nasef, M. M., Faridi-Majidi, R., Etesami, M., Takeshi, M., and AbouzariLotf, E. (2018). Highly flexible method for fabrication of poly (Glycidyl Methacrylate) grafted polyolefin nanofiber. Radiat. Phys. Chem. 151, 283-291. doi: 10.1016/j.radphyschem.2018.07.002

Abbasi, A., Nasef, M. M., Kheawhom, S., Faridi-Majidi, R., Takeshi, M., AbouzariLotf, E., et al. (2019). Amine functionalized radiation induced grafted polyolefin nanofibers for CO2 adsorption. Radiat. Phys. Chem. 156, 58-66. doi: 10.1016/j.radphyschem.2018.10.015

Abbasi, A., Nasef, M. M., Takeshi, M., and Faridi-Majidi, R. (2014). Electrospinning of nylon-6,6 solutions into nanofibers: rheology and morphology relationships. Chin. J. Polymer Sci. 32, 793-804. doi: 10.1007/s10118-014-1451-8

Abouzari-Lotf, E., Ghassemi, H., Nasef, M. M., Ahmad, A., Zakeri, M., Ting, T. M., et al. (2017). Phase separated nanofibrous anion exchange membranes with polycationic side chains. J. Mater. Chem. A 5, 15326-15341. doi: 10.1039/C7TA03967K

Alesi, W. R., and Kitchin, J. R. (2012). Evaluation of a primary aminefunctionalized ion-exchange resin for $\mathrm{CO} 2$ Capture. Industr. Eng. Chem. Res. 51, 6907-6915. doi: 10.1021/ie300452c

Aresta, M., and Quaranta, E. (1997). Carbon dioxide: a substitute for phosgene. CHEMTECH 27, 32-40.

Bondar, Y., Kim, H. J., Yoon, S. H., and Lim, Y. J. (2004). Synthesis of cationexchange adsorbent for anchoring metal ions by modification of poly(glycidyl methacrylate) chains grafted onto polypropylene fabric. React. Funct. Polymers 58, 43-51. doi: 10.1016/j.reactfunctpolym.2003.11.006

Chakarvarti, S. K., and Vetter, J. (1998). Template synthesis-a membrane based technology for generation of nano-/micro materials: a reviewl1Invited paper/talk at the 3rd International Conference and Intensive Tutorial course on Semiconductor Materials and Technology, Department of Electronic Science, University of Delhi South Campus, New Delhi, India, December 16-21, 1996. Radiat. Measur. 29, 149-159. doi: 10.1016/S1350-4487(98)00009-2

Choi, B., Panthi, D., Kwon, Y., and Tsutsumi, A. (2015). Chemical charging on a $\mathrm{MnO} 2$ electrode of a fuel cell/battery system in a highly $\mathrm{O} 2$-dissolved electrolyte. Electrochim. Acta 160, 323-329. doi: 10.1016/j.electacta.2015.02.023

Choi, S.-H., Lee, K.-P., and Nho, Y. C. (2001). Adsorption of urokinase by polypropylene films with various amine groups. J. Appl. Polymer Sci. 80, 2851-2858. doi: 10.1002/app.1402

Choi, S.-H., Nho, Y. C., and Kim, G.-T. (1999). Adsorption of Pb2+ and Pd2+ on polyethylene membrane with amino group modified by radiation-induced graft copolymerization. J. Appl. Polymer Sci. 71, 643-650.

\section{AUTHOR CONTRIBUTIONS}

AA, MN, RF-M, and MT: conceptualization. AA, MN, SK and EA-L: methodology. AA, FB, and TC: investigation. AA, FB, EA-L, and SK: data analysis. AA: writing-original draft preparation. MN, AS, SK, RF-M, EA-L, and TC: writing-review and editing. AA and EA-L: visualization. MN, RF-M, MT, and SK: supervision.

\section{FUNDING}

This research was supported by Chulalongkorn Academic Advancement into its 2nd Century Project, Chulalongkorn University.

\section{ACKNOWLEDGMENTS}

AA thanks the support from C2F Postdoctoral Fellowship, Chulalongkorn University.

Drese, J. H. (2010). The design, synthesis, and characterization of aminosilica adsorbents for $\mathrm{CO} 2$ capture from dilute sources (Ph.D.). Georgia Institute of Technology, Atlanta, GA, United States.

Gebald, C., Wurzbacher, J. A., Tingaut, P., Zimmermann, T., and Steinfeld, A. (2011). Amine-based nanofibrillated cellulose as adsorbent for CO2 capture from air. Environ. Sci. Technol. 45, 9101-9108. doi: 10.1021/es202223p

Graham, K., Ouyang, M., Raether, T., Grafe, T., Mcdonald, B., and Knauf, P. (2002). "Polymeric nanofibers in air filtration applications," in The Fifteenth Annual Technical Conference and Expo of the American Filtration and Separations Society (Texas, TX).

Heo, Y.-J., Zhang, Y., Rhee, K. Y., and Park, S.-J. (2019). Synthesis of PAN/PVDF nanofiber composites-based carbon adsorbents for CO2 capture. Comp. Part B Eng. 156, 95-99. doi: 10.1016/j.compositesb.2018.08.057

Hicks, J. C., Drese, J. H., Fauth, D. J., Gray, M. L., Qi, G., and Jones, C. W. (2008). Designing adsorbents for CO2 capture from flue gas-hyperbranched aminosilicas capable of capturing CO2 reversibly. J. Am. Chem. Soc. 130, 2902-2903. doi: 10.1021/ja077795v

Hong, S.-M., Kim, S. H., Jeong, B. G., Jo, S. M., and Lee, K. B. (2014). Development of porous carbon nanofibers from electrospun polyvinylidene fluoride for CO2 capture. RSC Adv. 4, 58956-58963. doi: 10.1039/C4RA 11290C

Hosseini, S., Marahel, E., Bayesti, I., Abbasi, A., Chuah Abdullah, L., and Choong, T. S. Y. (2015). CO2 adsorption on modified carbon coated monolith: effect of surface modification by using alkaline solutions. Appl. Surface Sci. 324, 569-575. doi: 10.1016/j.apsusc.2014.10.054

Iqbal, N., Wang, X., Yu, J., and Ding, B. (2017). Robust and flexible carbon nanofibers doped with amine functionalized carbon nanotubes for efficient CO2 capture. Adv. Sustain. Syst. 1:1600028. doi: 10.1002/adsu.201600028

Kim, D. W., Jung, D. W., Adelodun, A. A., and Jo, Y. M. (2017). Evaluation of CO2 adsorption capacity of electrospun carbon fibers with thermal and chemical activation. J. Appl. Polymer Sci. 134:45534. doi: 10.1002/app.45534

Ko, Y. G., Shin, S. S., and Choi, U. S. (2011). Primary, secondary, and tertiary amines for $\mathrm{CO} 2$ capture: designing for mesoporous $\mathrm{CO} 2$ adsorbents. J. Colloid Interface Sci. 361, 594-602. doi: 10.1016/j.jcis.2011.03.045

Li, P. Y., Ge, B. Q., Zhang, S. J., Chen, S. X., Zhang, Q. K., and Zhao, Y. N. (2008). $\mathrm{CO} 2$ capture by polyethylenimine-modified fibrous adsorbent. Langmuir 24, 6567-6574. doi: 10.1021/la800791s

Mahmoud Nasef, M., Abbasi, A., and Ting, T. M. (2014). New CO2 adsorbent containing aminated poly(glycidyl methacrylate) grafted onto irradiated PE-PP nonwoven sheet. Radiat. Phys. Chem. 103, 72-74. doi: 10.1016/j.radphyschem.2014.05.031 
Mittal, N., Samanta, A., Sarkar, P., and Gupta, R. (2015). Postcombustion CO2 capture using $\mathrm{N}$-(3-trimethoxysilylpropyl)diethylenetriamine-grafted solid adsorbent. Energy Sci. Eng. 3, 207-220. doi: 10.1002/ese3.64

Olivieri, L., Roso, M., De Angelis, M. G., and Lorenzetti, A. (2018). Evaluation of electrospun nanofibrous mats as materials for $\mathrm{CO} 2$ capture: a feasibility study on functionalized poly(acrylonitrile) (PAN). J. Membr. Sci. 546, 128-138. doi: 10.1016/j.memsci.2017.10.019

Schreuder-Gibson, H., Gibson, P., Senecal, K., Sennett, M., Walker, J., Yeomans, W., et al. (2002). Protective textile materials based on electrospun nanofibers. J. Adv. Mater. 34, 44-55.

Serna-Guerrero, R., and Sayari, A. (2010). Modeling adsorption of CO2 on aminefunctionalized mesoporous silica. 2: kinetics and breakthrough curves. Chem. Eng. J. 161, 182-190. doi: 10.1016/j.cej.2010.04.042

Van De Witte, P., Dijkstra, P. J., Van Den Berg, J. W. A., and Feijen, J. (1996). Phase separation processes in polymer solutions in relation to membrane formation. J. Membr. Sci. 117, 1-31. doi: 10.1016/0376-7388(96)00088-9

Wahiduzzaman, K. M., Absar, S., Harp, S., Edwards, K., and Takas, N. (2015). "Fabrication of polyacrylonitrile nanofiber membranes functionalized with metal organic framework for CO2 capturing," in ASME 2015 International Mechanical Engineering Congress and Exposition (Houston, TX). doi: 10.1115/IMECE2015-50806

Wang, Z., Zhao, C., and Pan, Z. (2015). Porous bead-on-string poly(lactic acid) fibrous membranes for air filtration. J. Colloid Interface Sci. 441, 121-129. doi: 10.1016/j.jcis.2014.11.041

Xiao, Q., Wen, J., Guo, Y., Hu, J., Wang, J., Zhang, F., et al. (2016). Synthesis, carbonization, and CO2 adsorption properties of phloroglucinol-melamine-formaldehyde polymeric nanofibers. Industr. Eng. Chem. Res. 55, 12667-12674. doi: 10.1021/acs.iecr.6b03494

Yun, K. M., Suryamas, A. B., Iskandar, F., Bao, L., Niinuma, H., and Okuyama, K. (2010). Morphology optimization of polymer nanofiber for applications in aerosol particle filtration. Separation Purif. Technol. 75, 340-345. doi: 10.1016/j.seppur.2010.09.002

Zainab, G., Iqbal, N., Babar, A. A., Huang, C., Wang, X., Yu, J., et al. (2017). Freestanding, spider-web-like polyamide/carbon nanotube composite nanofibrous membrane impregnated with polyethyleneimine for $\mathrm{CO} 2$ capture. Comp. Commun. 6, 41-47. doi: 10.1016/j.coco.2017.09.001

Zhuang, L., Chen, S., Lin, R., and Xu, X. (2013). Preparation of a solid amine adsorbent based on polypropylene fiber and its performance for $\mathrm{CO} 2$ capture. J. Mater. Res. 28, 2881-2889. doi: 10.1557/jmr.2013.278

Conflict of Interest: The authors declare that the research was conducted in the absence of any commercial or financial relationships that could be construed as a potential conflict of interest.

Copyright (c) 2019 Abbasi, Nasef, Babadi, Faridi-Majidi, Takeshi, AbouzariLotf, Choong, Somwangthanaroj and Kheawhom. This is an open-access article distributed under the terms of the Creative Commons Attribution License (CC BY). The use, distribution or reproduction in other forums is permitted, provided the original author(s) and the copyright owner(s) are credited and that the original publication in this journal is cited, in accordance with accepted academic practice. No use, distribution or reproduction is permitted which does not comply with these terms. 